\title{
Social Determinants of Active Aging: Differences in Mortality and the Loss of Healthy Life between Different Income Levels among Older Japanese in the AGES Cohort Study
}

\author{
Hiroshi Hirai, ${ }^{1}$ Katsunori Kondo, ${ }^{2}$ and Ichiro Kawachi ${ }^{3}$ \\ ${ }^{1}$ Department of Civil Environmental Engineering, Faculty of Engineering, Iwate University, Iwate, Morioka 020-8551, Japan \\ ${ }^{2}$ Center for Well-Being and Society, Nihon Fukushi University, Nagoya 460-0012, Japan \\ ${ }^{3}$ Department of Society, Human Development, and Health, Harvard School of Public Health, Boston, MA 02115, USA
}

Correspondence should be addressed to Hiroshi Hirai, hirai181kan@gmail.com

Received 2 May 2012; Accepted 12 August 2012

Academic Editor: Jean Marie Robine

Copyright ( $) 2012$ Hiroshi Hirai et al. This is an open access article distributed under the Creative Commons Attribution License, which permits unrestricted use, distribution, and reproduction in any medium, provided the original work is properly cited.

\begin{abstract}
We examined the relationship between income, mortality, and loss of years of healthy life in a sample of older persons in Japan. We analyzed 22,829 persons aged 65 or older who were functionally independent at baseline as a part of the Aichi Gerontological Evaluation Study (AGES). Two outcome measures were adopted, mortality and loss of healthy life. Independent variables were income level and age. The occurrence of mortality and need for care during these 1,461 days were tracked. Cox regressions were used to calculate the hazard ratio for mortality and loss of healthy life by income level. We found that people with lower incomes were more likely than those with higher incomes to report worse health. For the overall sample, using the governmental administrative data, the hazard ratios of mortality and loss of healthy life-years comparing the lowest to the highest income level were 3.50 for men and 2.48 for women for mortality and 3.71 for men and 2.27 for women for loss of healthy life. When only those who responded to questions about income on the mail survey were included in the analysis, the relationships became weaker and lost statistical significance.
\end{abstract}

\section{Introduction}

There is a well-established inverse relationship between income and health [1-7]. However, many of the studies reporting on this relationship have used mortality as an indicator of health. In evaluating health, the World Health Organization recommends using indicators that reflect quality of life (QOL), such as healthy life expectancy, which measures active aging. Active aging aims to extend healthy life expectancy and quality of life in older persons, and the quality of life is largely determined by its ability to maintain autonomy and independence [8]. Fewer studies use active aging as an endpoint because these measures, unlike measures of mortality, require investigation into the physical and cognitive functioning of surviving participants. As a result, in large-scale cohort studies it is much more difficult and costly to follow functional status over a long period than to simply follow mortality.
Measuring income is a difficult issue in studies that investigate the relationship between income and health. Individuals with lower socioeconomic status (SES) tend to be less likely to respond to surveys by mail or similar means. In addition, income data are often unreliable or missing for a large part of the sample [9]. Therefore, lower income groups, which are predicted to be the least healthy, are not well represented. This underrepresentation gives rise to the possibility of underestimating the inequality in health. However, while this problem has been acknowledged, there are no studies that have compared analyses using government statistical data, which have almost no missing data, and analyses of survey respondent data to investigate the existence and size of underevaluation of the income inequality.

Fortunately, we have been able to overcome the issues involved in conducting a large-scale cohort study that monitors functional status and obtaining income data from both surveys and local government statistics. The Japanese 
government introduced a public long-term care insurance system in 2000. Insurance applicants are assessed using standard criteria for physical and cognitive functioning to determine eligibility. Long-term care insurance premiums are imposed on everyone 65 years of age or older who is insured under the long-term care insurance system. These premiums are set according to income level, which is determined by the municipality in which the insured person lives.

In this study, we used representative sample data of five municipalities that contains information on physical and cognitive functional declines and income data from the government to examine the relationship between health and income. In addition, we conducted a survey by mail, and using this government data and data on responses to income items in the mail survey, we investigated the effect of differential response in income self-reports among the elderly.

Measuring the inequality in health using Japanese data is also thought to be meaningful in other ways, as the healthy life expectancy in Japan is among the longest in the world [10]. In addition to background factors, such as improved medical services and dietary habits that come with universal healthcare and economic growth, the equitableness of Japanese society, with small inequalities among people, has attracted attention as a possible reason $[11,12]$. In a recent meta-analysis, health levels are reported to be lower among people living in countries with a large Gini coefficient and very unequal income distributions [13].

However, since the 1990s, the Gini coefficient has been rising in Japan as the income inequality has widened. There is concern that in the coming years the inequality in health will continue to grow in Japan, making it similar to other developed countries. However, there are particularly few investigations on the relationship between income and health in Japan. Moreover, most of the studies that have been conducted on this subject are ecological studies, such as the studies by Fukuda and colleagues $[14,15]$ that show a relationship between income level and mortality in communities. The only cohort study that we are aware of was conducted by Kimura and colleagues [16]. This study demonstrated an association with mortality using scores (0-6) prepared from six dichotomous indicators related to income. No studies have investigated the relationship between quantitative income and health at the individual level [17].

\section{Objectives}

The purpose of this study was to investigate the relationship between health and income using a prospective cohort study design. The investigation was dually focused and included (1) an investigation of the relationship between mortality and income and loss of healthy life and income; (2) a comparison of responders of a self-administered mail survey to a sample of elderly people, including those who did not respond to the survey, to investigate differences in the income-health relationship in the two samples.

\section{Materials and Methods}

3.1. Study Population. The present study is based on data from the Aichi Gerontological Evaluation Study Project. The project is an ongoing prospective cohort study that started in two municipalities in Aichi Prefecture, Japan, in 1999. The project focuses on elderly people aged 65 years and older who are independent in physical and cognitive functioning. In second wave surveys of this project, research results are being accumulated with a focus on cross-sectional data obtained in fiscal 2003 from 15 municipalities in three prefectures [18-21]. Currently, follow-up data on certification of longterm care need and mortality are being obtained for the municipalities that cooperated in this study and from among the municipalities that are the subjects of second wave surveys. There are several published articles using this cohort data [22-24].

The present study looked at elderly people 65 years of age or older living in five municipalities that provided income data. Ethical approval for the study was obtained from the Nihon Fukushi University ethics committee.

3.2. Participants. Self-administered questionnaires completed by elderly people 65 and older living in one of five participating municipalities were collected by mail in October 2003. The questionnaire included items that asked about the physical, mental, and social situation of respondents. Of the 24,374 people selected to receive the survey by the municipalities, those who had been certified as needing long-term care as of October 31, 2003 were excluded, and the remaining 22,829 people were included as subjects in the present analysis. The mean age $\pm \mathrm{SD}$ of the subjects was $73 \pm 6.3$ years, and there were 10,290 men and 12,593 women.

The age and income level distribution of the entire sample is shown in Table 2. The standards were the same for men and women, but the distribution for men and women differed. More than $20 \%$ of men were in the fifth level and more than $50 \%$ were in the fourth and fifth levels combined. In comparison, less than $10 \%$ of the women were in the fourth and fifth levels combined. Here are some reasons for the gender difference in income. First, the greater part of Japanese women was full-time housewives. Full-time housewives were not obliged to enroll in the national pension scheme until 1985, so some part of them had not participated in the national pension and they receive lower pension benefits. Second, the percentage of older women living alone exceeds that of men. According to the 2000 national census, the living alone rate for older women is 17.9 percent, compared to 8.0 percent for men. Single households have considerably lower household income than other household type. Table 3 shows the number of people and percentage that responded to the survey and to questions about income by age and income level. There was a tendency for both men and women in high income groups to have a high response rate. 
TABLE 1: Income level.

\begin{tabular}{llc}
\hline Income level & Eligible persons & Premium \\
\hline & Public assistance recipients & Basic amount $\times 0.5$ \\
Level 1 & Municipal tax-exempted households and old-age welfare & \\
& $\quad$ Pension recipients & Basic amount $\times 0.75$ \\
Level 2 & Municipal tax-exempted households & Basic amount $\times 1$ \\
Level 3 & Municipal tax-exempted persons & Basic amount $\times 1.25$ \\
Level 4 & Municipal tax payer (the insured person's total amount of income is less than 2,500,000 yen) & Basic amount $\times 1.5$ \\
Level 5 & Municipal tax payer (the insured person's total amount of income is 2,500,000 yen or more) &
\end{tabular}

\subsection{Measures}

3.3.1. Dependent Variables. Two outcome measures were adopted, mortality and loss of healthy life. Data were collected from the public long-term care insurance database maintained by each participating municipality. Mortality was ascertained using the insured person list of the public longterm care insurance. Loss of healthy life was defined as mortality, functional decline, or cognitive impairment. The condition of "functional decline or cognitive impairment" means a condition assumed to require care on a continual and steady basis for the whole or a part of basic movements in daily activities. Functional decline or cognitive impairment assessed using standards presented by the national government, an examination of mental and physical status based on a visiting survey to maintain objectivity and reliability and make a screening judgment based on the opinions of a regular doctor [25].

3.3.2. Independent Variables. Income level was based on calculations used to determine long-term care insurance premiums, since long-term care insurance premiums in Japan are determined based on income level (Table 1). Subjects who are exempt from the municipal residence tax earn an income of less than 1.25 million yen according to criteria set in 2003 .

3.3.3. Statistical Methods. The study sample were followed from November 1, 2003 to October 31, 2007. The occurrence of mortality and need for care during these 1,461 days were tracked. Cox proportional hazard models were used to calculate the hazard ratio (HR) and 95\% confidence intervals (CIs) for mortality and loss of healthy life by income level. All analyses were stratified by gender. In addition, an analysis including only subjects who responded to questions about income on the self-administered survey was conducted, and results were compared.

\section{Results}

4.1. Aggregate Totals, Number of Outcome Events, and Rates of Mortality and Certification of Long-Term Care Need during the Follow-Up Period. There were 1,328 deaths among men and 944 deaths among women in over 38,442 person-years of observation in men and 48,120 person-years in women. Loss of healthy life was observed in 2,157 men and 2,636 women in over 36,565 person-years of observation in men and
44,483 person-years in women. Followup was not possible for 113 men and 162 women either because they moved out of the area or for other reasons.

4.2. Main Results. Table 4 shows the age-adjusted hazard ratios for community-dwelling independent elderly. In men, using death as the endpoint and income level 5 as the reference, hazard ratios reached statistical significance from level 3 (HR 1.55, 95\% CI 1.31-1.84) to level 1 (HR 3.50, 95\% CI 1.91-6.42). When loss of healthy life was the endpoint, hazard ratios were statistically significant for all income levels compared to income level 5; from level 4 (HR 1.23, 95\% CI 1.07-1.41) to level 1 (HR 3.71, 95\% CI 2.24-6.13). Among women, when mortality was the endpoint, hazard ratios were statistically significant for level 1 compared to level 5 (HR 2.48, 95\% CI 1.09-5.67). When loss of healthy life was the endpoint, hazard ratios were statistically significant for level 2 (HR 1.41, 95\% CI 1.10-1.81) and level 1 (HR 2.27, 95\% CI 1.43-3.63) compared to level 5.

In contrast, when only those who responded to questions about income on the mail survey were included in the analysis, among men, the hazard ratio, comparing the lowest to the highest income level, was smaller than with the full sample, and, among women, the relationship between income and health was no longer significant.

\section{Discussion}

5.1. Key Results. Our study analyzed government health data of independent elderly, and we found that people with lower incomes were more likely than people with higher incomes to lose their health when using both mortality and loss of healthy life as endpoints. The hazard ratio comparing the lowest income level to the highest income level was 3.50 for men and 2.48 for women when using mortality as an endpoint and 3.71 for men and 2.27 for women when using loss of healthy life as an endpoint. When only those who responded to questions about income on the mail survey were included in the analysis, the relationship became weaker.

5.2. Limitations. This study has the following limitations. The government data only included information on the taxable income of the individual. Thus, the income of other household members remained unclear. Further, the study only considered income, and accumulated wealth or assets were not included in the analysis. Therefore, in some cases, 
TABLE 2: Baseline distribution of data on age and income level.

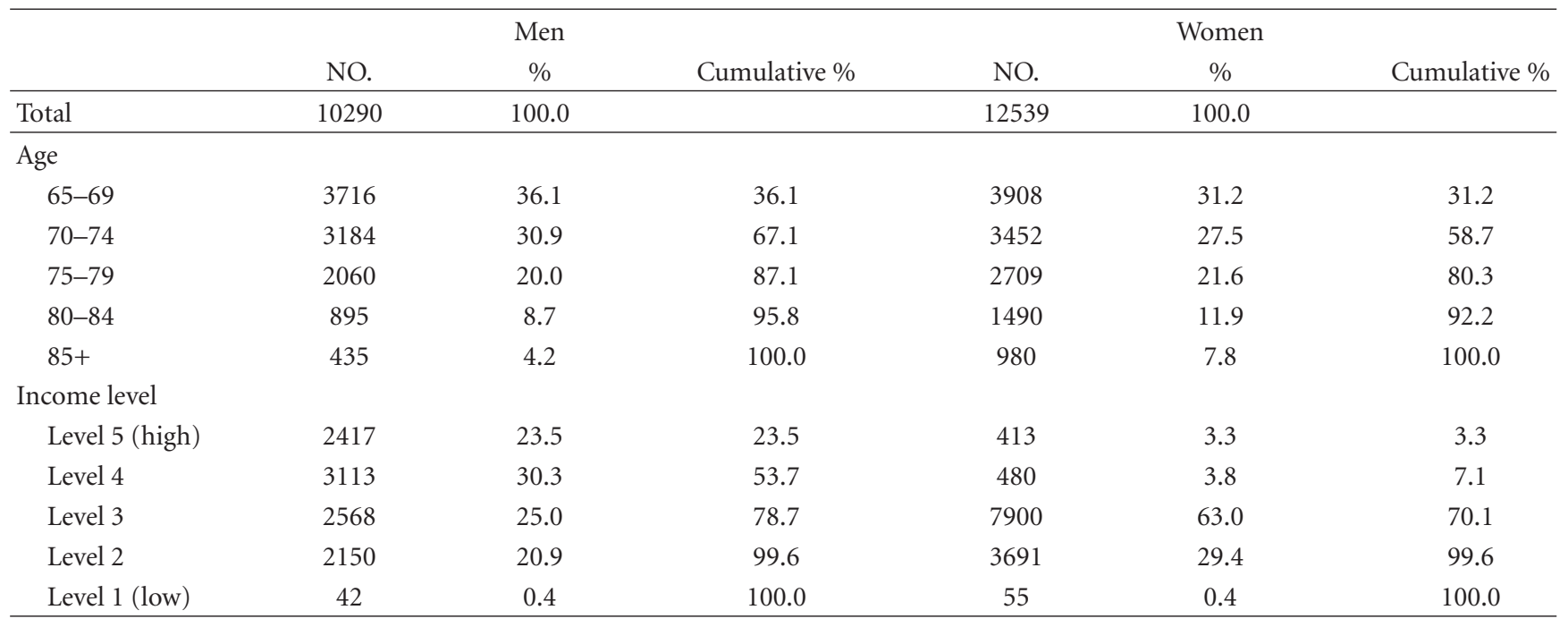

TABLE 3: Respondents rate for mail survey and item about income.

\begin{tabular}{|c|c|c|c|c|c|c|}
\hline & & $\begin{array}{l}\text { Whole sample } \\
\text { (A) }\end{array}$ & $\begin{array}{l}\text { Number of } \\
\text { respondents for } \\
\text { mail survey (B) }\end{array}$ & $\begin{array}{c}\text { Respondents rate } \\
(\mathrm{B} / \mathrm{A}, \%)\end{array}$ & $\begin{array}{c}\text { Number of } \\
\text { respondents for item } \\
\text { about income }(\mathrm{C})\end{array}$ & $\begin{array}{c}\text { Respondents rate for } \\
\text { item about income } \\
(\mathrm{C} / \mathrm{A}, \%)\end{array}$ \\
\hline & Total & 10290 & 5513 & 53.6 & 4824 & 46.9 \\
\hline & Age & & & & & \\
\hline & $65-69$ & 3716 & 2016 & 54.3 & 1854 & 49.9 \\
\hline & $70-74$ & 3184 & 1666 & 52.3 & 1469 & 46.1 \\
\hline & $75-79$ & 2060 & 1112 & 54.0 & 939 & 45.6 \\
\hline & $80-84$ & 895 & 498 & 55.6 & 389 & 43.5 \\
\hline \multirow[t]{13}{*}{ Men } & $85+$ & 435 & 221 & 50.8 & 173 & 39.8 \\
\hline & Income level & & & & & \\
\hline & Level 5 (high) & 2417 & 1434 & 59.3 & 1332 & 55.1 \\
\hline & Level 4 & 3113 & 1920 & 61.7 & 1744 & 56.0 \\
\hline & Level 3 & 2568 & 1146 & 44.6 & 890 & 34.7 \\
\hline & Level 2 & 2150 & 1007 & 46.8 & 854 & 39.7 \\
\hline & Level 1 (low) & 42 & 6 & 14.3 & 4 & 9.5 \\
\hline & Total & 12539 & 6375 & 50.8 & 4467 & 35.6 \\
\hline & Age & & & & & \\
\hline & $65-69$ & 3908 & 2012 & 51.5 & 1599 & 40.9 \\
\hline & $70-74$ & 3452 & 1767 & 51.2 & 1286 & 37.3 \\
\hline & $75-79$ & 2709 & 1446 & 53.4 & 934 & 34.5 \\
\hline & $80-84$ & 1490 & 754 & 50.6 & 417 & 28.0 \\
\hline \multirow[t]{7}{*}{ Women } & $85+$ & 980 & 396 & 40.4 & 231 & 23.6 \\
\hline & Income level & & & & & \\
\hline & Level 5 ( high) & 413 & 223 & 54.0 & 172 & 41.6 \\
\hline & Level 4 & 480 & 266 & 55.4 & 209 & 43.5 \\
\hline & Level 3 & 7900 & 4042 & 51.2 & 2772 & 35.1 \\
\hline & Level 2 & 3691 & 1827 & 49.5 & 1308 & 35.4 \\
\hline & Level 1 (low) & 55 & 17 & 30.9 & 6 & 10.9 \\
\hline
\end{tabular}




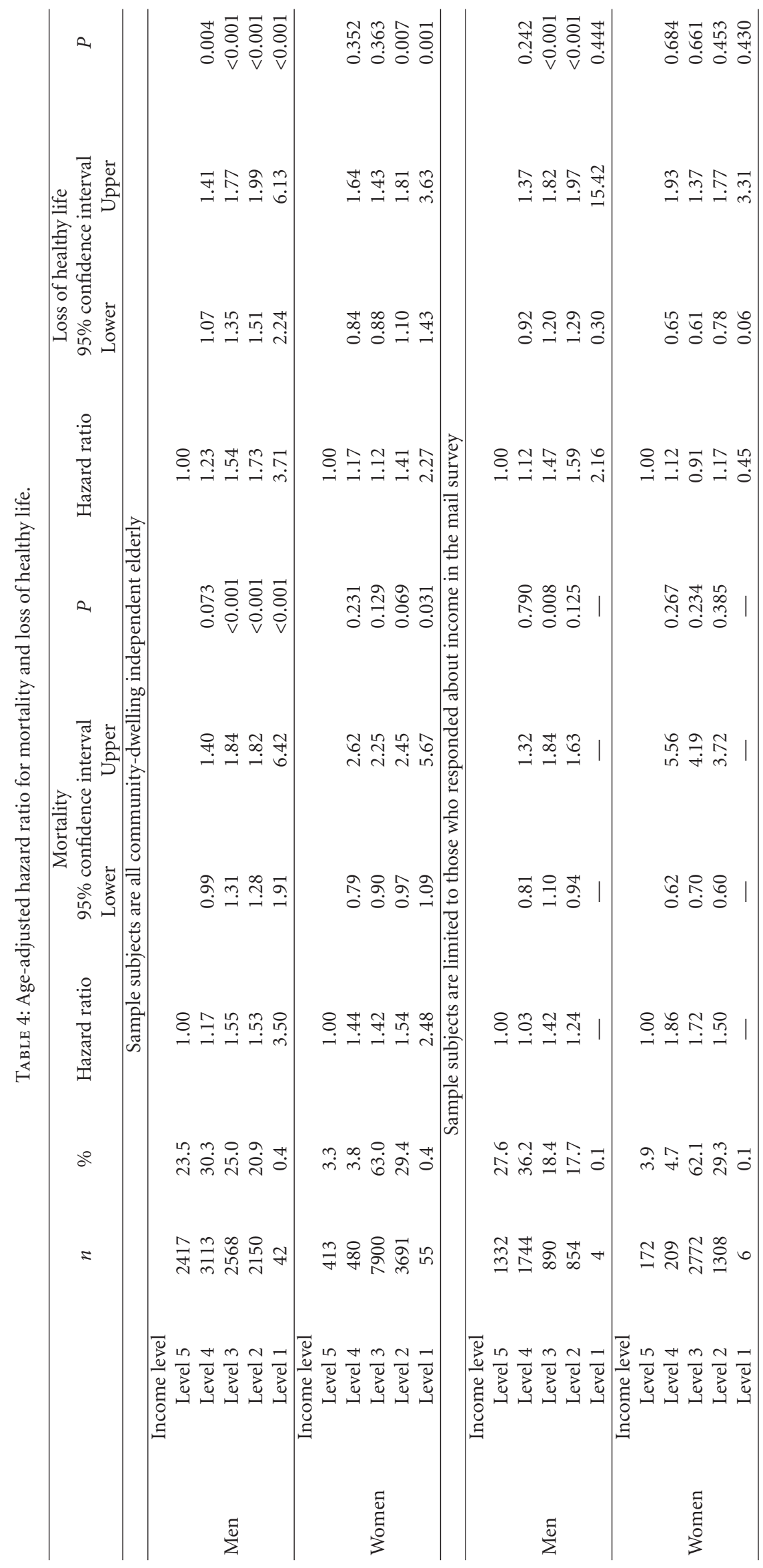


these data may not reflect actual economic affluence. In addition, since data other than income, age, and sex were not obtained, there may have been confounding factors that we were unable to adjust for. Hence, these results do not mean a causal link but an observational relationship including confounders such as education level and behavioural risk factors.

5.3. Interpretation. This study provides several findings not reported in previous studies. First, the results of this study verifies, using a large dataset with a high follow-up rate (98.8\%), the relationship between low income, mortality, and risk of decreased physical and cognitive functioning in a sample of older adults. It is difficult to ensure a high followup rate in cohort studies that use functional decline as the endpoint. For example, Beydoun and Popkin [4] followed a sample of 976 out of the original 1,385 subjects (followup rate: $70.5 \%$ ) for three years, Lynch and colleagues [26] followed a sample of 1,124 out of 1,799 subjects (followup rate: $62.4 \%$ ) for 11 years, and Guralnik and Kaplan [5] followed a sample of 496 out of 2,392 subjects (follow-up rate: $20.7 \%$ ) for 19 years. Second, by comparing all independent elderly included in the government data to those who responded to questions on income in a mail survey, we demonstrated that measurement of the inequality in health is underestimated because individuals with low SES are less likely respond to self-administered surveys.

The finding that the relationship between SES and health indicators is stronger for men than women has been reported in many studies. There are also reports, such as that of Bassuk and colleagues [27], of a strong association between income and mortality in women. In the present study, significantly larger hazard ratios were obtained for men compared to those for women for both mortality and loss of healthy life. However, there are large differences between men and women in the distribution of income, and so when comparing the size of hazard ratios in men and women, due consideration should be given in the comparison of percentile in the groups from which the reference and HR are obtained. Men in the fifth income level corresponding to high income were the top 23.5 percentiles, while women were the top 3.3 percentiles. Since women are understood to be in a higher level, hazard ratios would tend to be larger in women than in men when obtaining the hazard ratios of the lower levels. However, in fact, the hazard ratios for women are smaller than in men. If the top 20 percentiles are taken as the reference for women the same as in men, hazard ratios may become even smaller. Thus, the relation between income and health is thought to be stronger in men than in women.

Our results demonstrated that men and women with low income levels are less healthy than people with high income levels. We compared our results to those of previous studies conducted in other countries. Since income distributions differed among studies, we took this into consideration when comparing results. In the present study, the percentage of people with the lowest income (level 1) was small. Further, people in income level 1 may be more likely to receive certification of long-term care need compared to people of income level 2 or higher, since people receiving public assistance do not pay for care services. As a result, we used income level 2 for comparison, which corresponds roughly to the 20th percentile from the bottom in men and the 30th percentile in women.

Looking at mortality in this study, the HR was 1.53 in men of the level 2 group, which corresponded to $78.7-99.6 \%$ from the top, compared to the reference category (level 5) which is $0-23.5 \%$ from the top. In previous studies listed in Table 5 (see Osler et al. [28] and Manor et al. [29]) the top $25 \%$ was used as the reference group, similar to the present study. Osler and colleagues reported a slightly higher HR of 1.92 for a comparison of similar groups. Manor and colleagues reported an HR of 1.61 for the 75100 percentiles, similar to our level 2 group, which can be com-pared to the HR of 1.53 found in our study. In women, the HR comparing the level 2 group, which corresponded to 70.1-99.6 percentiles, to the reference category, which corresponded to the 3.3 percentile, was 1.54 . In a study that looked at women 65 years of age, Bassuk and colleagues [27] reported an HR of 2.13 for the 49-100 percentiles compared to the top $5.9 \%$, similar to the reference group used in the present study. Finally, Martikainen and colleagues [9] reported an HR of 1.47 for 70-80 percentiles compared to the top $10 \%$ and an HR of 1.51 for the $80-90$ percentiles compared to the top $10 \%$. These findings are similar to those found in the present study, as we found an HR of 1.54 for the level 2 group, which corresponds to the 70.1-99.6 percentiles. We take these similarities between our results and those of previous studies as evidence that, while the inequality in health in Japan is not large compared to other countries, neither is it particularly small.

In the present study, the HR for loss of healthy life among men that compared the 78.7-99.6 percentiles to the top 23.5 percent was 1.73. For women, the HR comparing the bottom 70.1-99.6 percentiles to the top 2.3 percent was 1.41. In contrast, Beydoun and Popkin [4], who looked at declining ADL or IADL, reported an HR of 1.69 when comparing the 70100 percentiles to the top 20 percent.

When comparing our results for all independent elderly to our results for those who responded to questions about income in the mail survey, we found that the hazard ratios were lower for those that responded to the survey for both mortality and loss of healthy life, and, for women that responded to the survey, hazard ratios did not reach statistical significance. These results provide evidence that, when evaluating the inequality in health, underestimation may occur if subjects are limited to people who respond to income items on self-administered mail surveys, and the real inequality in health may not be detected.

Hirdes and Forbes [2] conducted a study using data from the 1995 National Livelihood Survey in Japan and found a lack of support for the relative income hypothesis, which is consistent with the view expressed by Marmot and Smith [11] and Wilkinson [12]. However, Oshio and Kobayashi [30], using National Livelihood Survey data from 2004, and Ichida and colleagues [19], using data from a 2003 independent survey, found that the relative income hypothesis was supported. These differences may be because Japan has entered a period of breakdown in its traditional social 


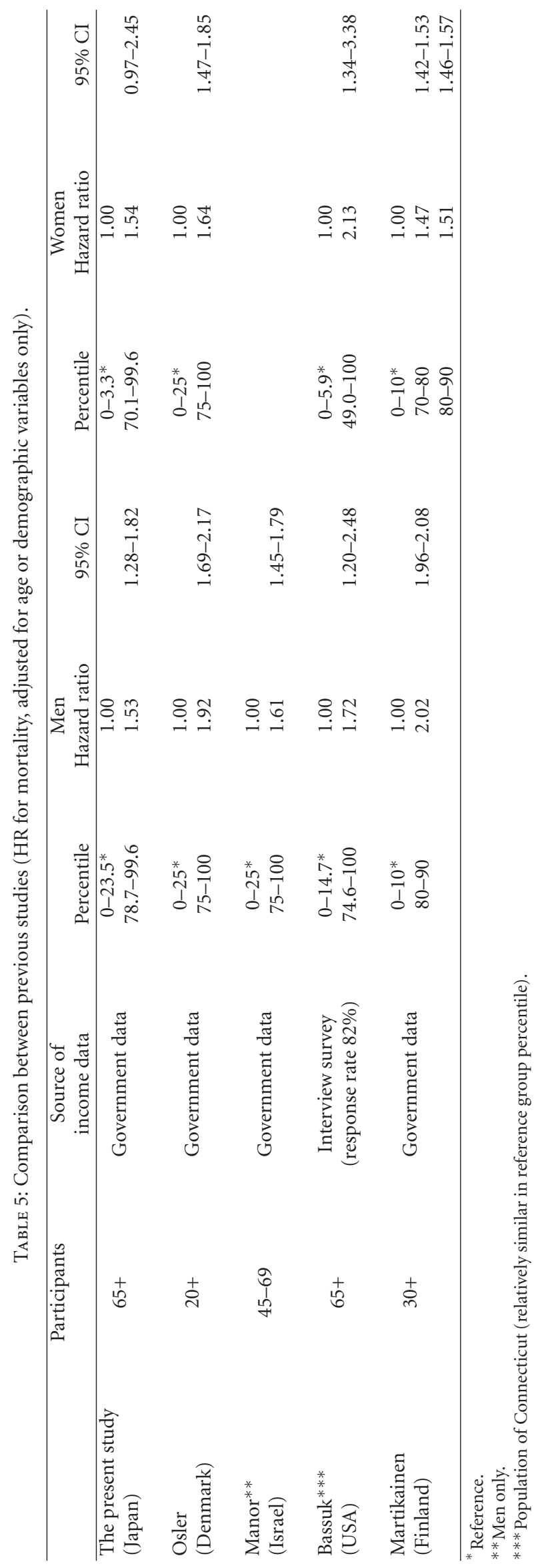


structure (Kagamimori et al. [17]), and socioeconomic inequality in Japan seems to be associated with more serious health consequences. The present study used 2003 data. The inequality in health in Japan may be growing larger as a result of the recent expansions in the income inequality.

\section{Conclusion}

We revealed that the lower income was a significant negative social determinant of active aging with a hazard ratio of 3.712.27 for the lowest income people. This was the first cohort study in Japan to examine the relationship between income, mortality, and declines in physical and cognitive functioning using individual level local government data with a high follow-up rate. In addition, we demonstrated that, due to missing data, the inequality in health may be underestimated when data are gathered using self-administered mail surveys.

It is meaningful that the present results, which avoided underestimation of the inequality in health, provided evidence that the inequality in health among older Japanese is similar to that found in other countries. While there is great variety in the measures taken by governments against the inequality in health, from ignoring the inequality altogether to adopting comprehensive, coordinated policies, in Japan and many other countries, measurement of the inequality in health is inadequate (Whitehead [31], Kondo [32]). Thus, measuring the inequality in health is an important first step in beginning to resolve it. Measuring the inequality in health in future surveys in all parts of the country and clarifying the status of these inequalities in health will provide clues for taking the next step necessary to correct the inequality in health and facilitate active aging.

\section{Acknowledgments}

This study used data from the Aichi Gerontological Evaluation Study (AGES). This study was organized by Center for Well-being and Society, the Nihon Fukushi University, supported in part by a grant of Strategic Research Foundation Grant-aided Project for Private Universities from Ministry of Education, Culture, Sport, Science, and Technology, Japan (MEXT), 2009-2013. This study was supported by the Grantin-Aid for Scientific Research (KAKENHI 23243070) from the Japan Society for the Promotion of Science. The authors have no conflict of interests to declare.

\section{References}

[1] A. Antonovsky, "Social class, life expectancy and overall mortality," The Milbank Memorial Fund Quarterly, vol. 45, no. 2, pp. 31-73, 1967.

[2] J. P. Hirdes and W. F. Forbes, "The importance of social relationships, socioeconomic status and health practices with respect to mortality among healthy Ontario males," Journal of Clinical Epidemiology, vol. 45, no. 2, pp. 175-182, 1992.

[3] M. G. Marmot, M. J. Shipley, and G. Rose, "Inequalities in death: specific explanations of a general pattern?" Lancet, vol. 1, no. 8384, pp. 1003-1006, 1984.
[4] M. A. Beydoun and B. M. Popkin, "The impact of socioeconomic factors on functional status decline among community-dwelling older adults in China," Social Science and Medicine, vol. 60, no. 9, pp. 2045-2057, 2005.

[5] J. M. Guralnik and G. A. Kaplan, "Predictors of healthy aging: prospective evidence from the Alameda County Study," American Journal of Public Health, vol. 79, no. 6, pp. 703-708, 1989.

[6] J. M. Guralnik, A. Z. LaCroix, R. D. Abbott et al., "Maintaining mobility in late life. I. Demographic characteristics and chronic conditions," American Journal of Epidemiology, vol. 137, no. 8, pp. 845-857, 1993.

[7] C. K. Nordstrom, A. V. Diez Roux, R. Schulz, M. N. Haan, S. A. Jackson, and J. L. Balfour, "Socioeconomic position and incident mobility impairment in the Cardiovascular Health Study," BMC Geriatrics, vol. 7, article no. 11, 2007.

[8] World Health Organization, "Active aging a policy framework," Tech. Rep. WHO/NMH/NPH/02.8, World Health Organization, Geneva, Switzerland, 2002.

[9] P. Martikainen, P. Mäkelä, S. Koskinen, and T. Valkonen, "Income differences in mortality: a register-based follow-up study of three million men and women," International Journal of Epidemiology, vol. 30, no. 6, pp. 1397-1405, 2001.

[10] World Health Organization, "Mental health: new understanding, new hope," World Health Report 2001, World Health Organization, Geneva, Switzerland, 2001.

[11] M. G. Marmot and G. D. Smith, "Why are the Japanese living longer?” BMJ, vol. 299, no. 6715, pp. 1547-1551, 1989.

[12] R. G. Wilkinson, "Income distribution and life expectancy," BMJ, vol. 304, no. 6820, pp. 165-168, 1992.

[13] N. Kondo, G. Sembajwe, I. Kawachi, R. M. van Dam, S. V. Subramanian, and Z. Yamagata, "Income inequality, mortality, and self rated health: meta-analysis of multilevel studies," BMJ, vol. 339, article b4471, 2009.

[14] Y. Fukuda, K. Nakamura, and T. Takano, "Higher mortality in areas of lower socioeconomic position measured by a single index of deprivation in Japan," Public Health, vol. 121, no. 3, pp. 163-173, 2007.

[15] Y. Fukuda, K. Nakamura, and T. Takano, "Municipal socioeconomic status and mortality in Japan: sex and age differences, and trends in 1973-1998," Social Science and Medicine, vol. 59, no. 12, pp. 2435-2445, 2004.

[16] E. Kimura, A. Goto, M. Tsunoda, S. Yasumura, and S. Sakihara, "Socioeconomic status and total mortality among the Japanese elderly:review of the literature and analysis of cohort data from the elderly in Ohgimi village, Okinawa," The Fukushima Medical Journal, vol. 53, pp. 345-354, 2003.

[17] S. Kagamimori, A. Gaina, and A. Nasermoaddeli, "Socioeconomic status and health in the Japanese population," Social Science and Medicine, vol. 68, no. 12, pp. 2152-2160, 2009.

[18] C. Murata, K. Kondo, H. Hirai, Y. Ichida, and T. Ojima, "Association between depression and socio-economic status among community-dwelling elderly in Japan: the Aichi Gerontological Evaluation Study (AGES)," Health and Place, vol. 14, no. 3, pp. 406-414, 2008.

[19] Y. Ichida, K. Kondo, H. Hirai, T. Hanibuchi, G. Yoshikawa, and C. Murata, "Social capital, income inequality and self-rated health in Chita peninsula, Japan: a multilevel analysis of older people in 25 communities," Social Science and Medicine, vol. 69, no. 4, pp. 489-499, 2009.

[20] C. Murata, T. Yamada, C. C. Chen, T. Ojima, H. Hirai, and K. Kondo, "Barriers to health care among the elderly in Japan," International Journal of Environmental Research and Public Health, vol. 7, no. 4, pp. 1330-1341, 2010. 
[21] T. Hanibuchi, J. Aida, M. Nakade, H. Hirai, and K. Kondo, "Geographical accessibility to dental care in the Japanese elderly," Community Dental Health, vol. 28, no. 2, pp. 128-135, 2011.

[22] N. Kondo, I. Kawachi, H. Hirai et al., "Relative deprivation and incident functional disability among older Japanese women and men: prospective cohort study," Journal of Epidemiology and Community Health, vol. 63, no. 6, pp. 461-467, 2009.

[23] J. Aida, T. Hanibuchi, M. Nakade, H. Hirai, K. Osaka, and K. Kondo, "The different effects of vertical social capital and horizontal social capital on dental status: a multilevel analysis," Social Science and Medicine, vol. 69, no. 4, pp. 512-518, 2009.

[24] A. Nishi, K. Kondo, H. Hirai, and I. Kawachi, "Cohort profile: the AGES 2003 cohort study in Aichi, Japan," Journal of Epidemiology, vol. 21, no. 2, pp. 151-157, 2011.

[25] T. Tsutsui and N. Muramatsu, "Care-needs certification in the long-term care insurance system of Japan," Journal of the American Geriatrics Society, vol. 53, no. 3, pp. 522-527, 2005.

[26] J. W. Lynch, G. A. Kaplan, and S. J. Shema, "Cumulative impact of sustained economic hardship on physical, cognitive, psychological, and social functioning," New England Journal of Medicine, vol. 337, no. 26, pp. 1889-1895, 1997.

[27] S. S. Bassuk, L. F. Berkman, and B. C. Amick, "Socioeconomic status and mortality among the elderly: findings from four US communities," American Journal of Epidemiology, vol. 155, no. 6, pp. 520-533, 2002.

[28] M. Osler, E. Prescott, M. Grønbæk, U. Christensen, P. Due, and G. Engholm, "Income inequality, individual income, and mortality in danish adults: Analysis of pooled data from two cohort studies," BMJ, vol. 324, no. 7328, pp. 13-16, 2002.

[29] O. Manor, Z. Eisenbach, E. Peritz, and Y. Friedlander, "Mortality differentials among Israeli men," American Journal of Public Health, vol. 89, no. 12, pp. 1807-1813, 1999.

[30] T. Oshio and M. Kobayashi, "Income inequality, area-level poverty, perceived aversion to inequality, and self-rated health in Japan," Social Science and Medicine, vol. 69, no. 3, pp. 317326, 2009.

[31] M. Whitehead, "Diffusion of Ideas on Social Inequalities in Health: a European perspective," Milbank Quarterly, vol. 76, no. 3, pp. 469-492, 1998.

[32] K. Kondo, "Comprehensive strategy for inequality in health based on results of Europe," The Japanese Journal For Public Health Nurse, vol. 63, pp. 444-450, 2007 (Japanese). 


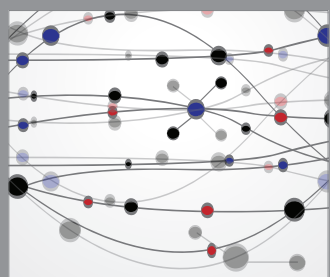

The Scientific World Journal
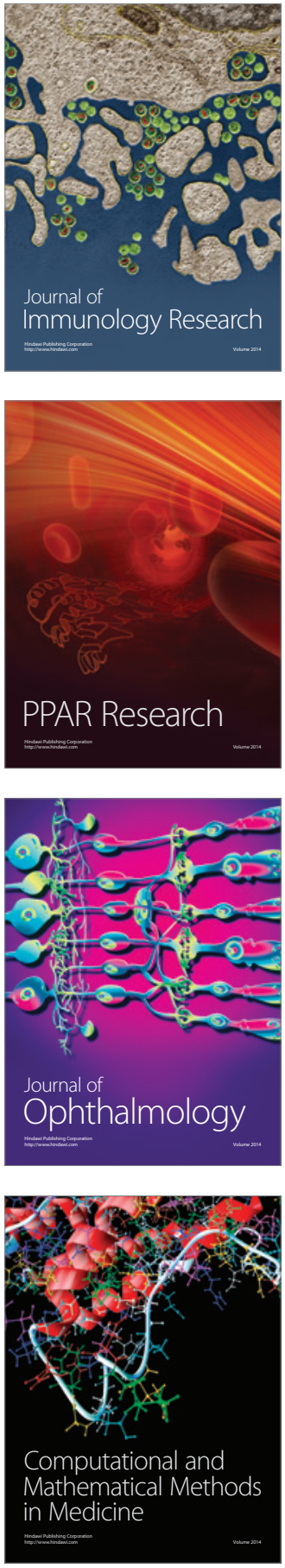

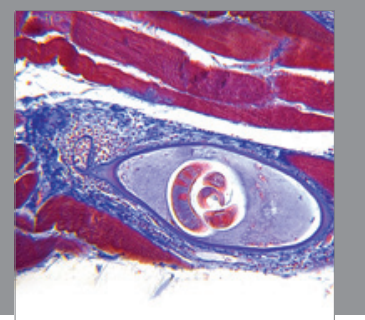

Gastroenterology

Research and Practice
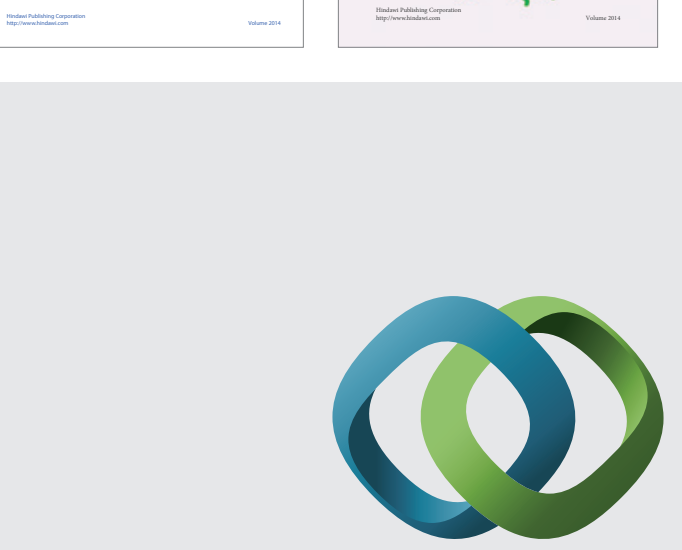

\section{Hindawi}

Submit your manuscripts at

http://www.hindawi.com
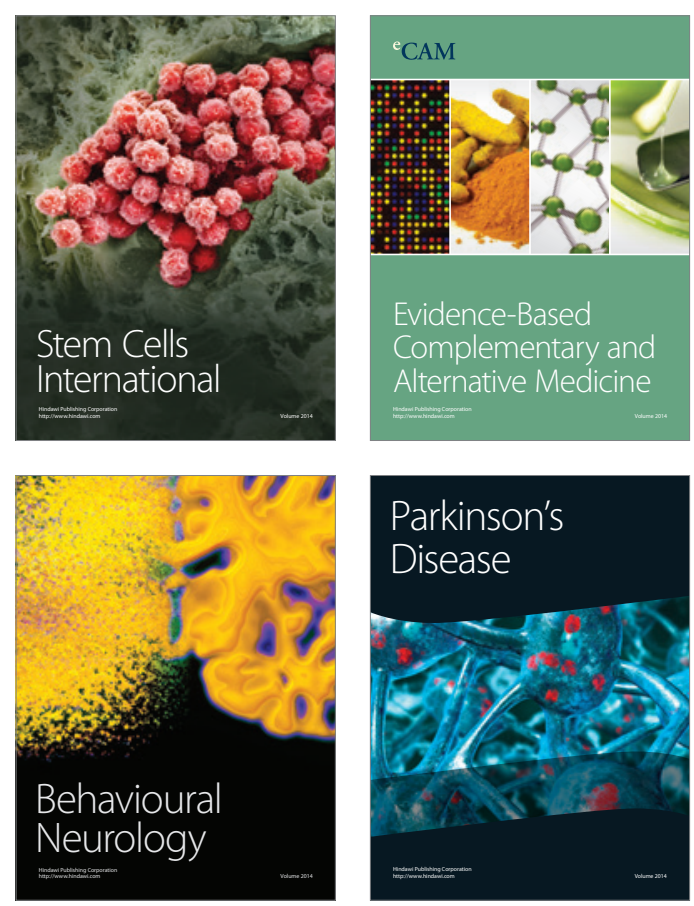

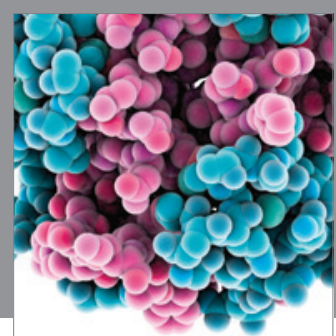

Journal of
Diabetes Research

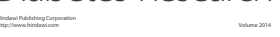

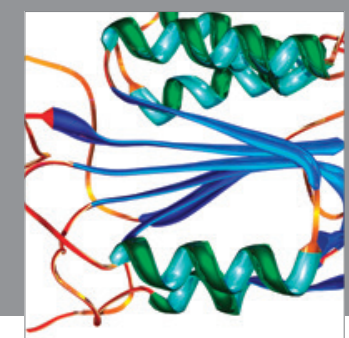

Disease Markers
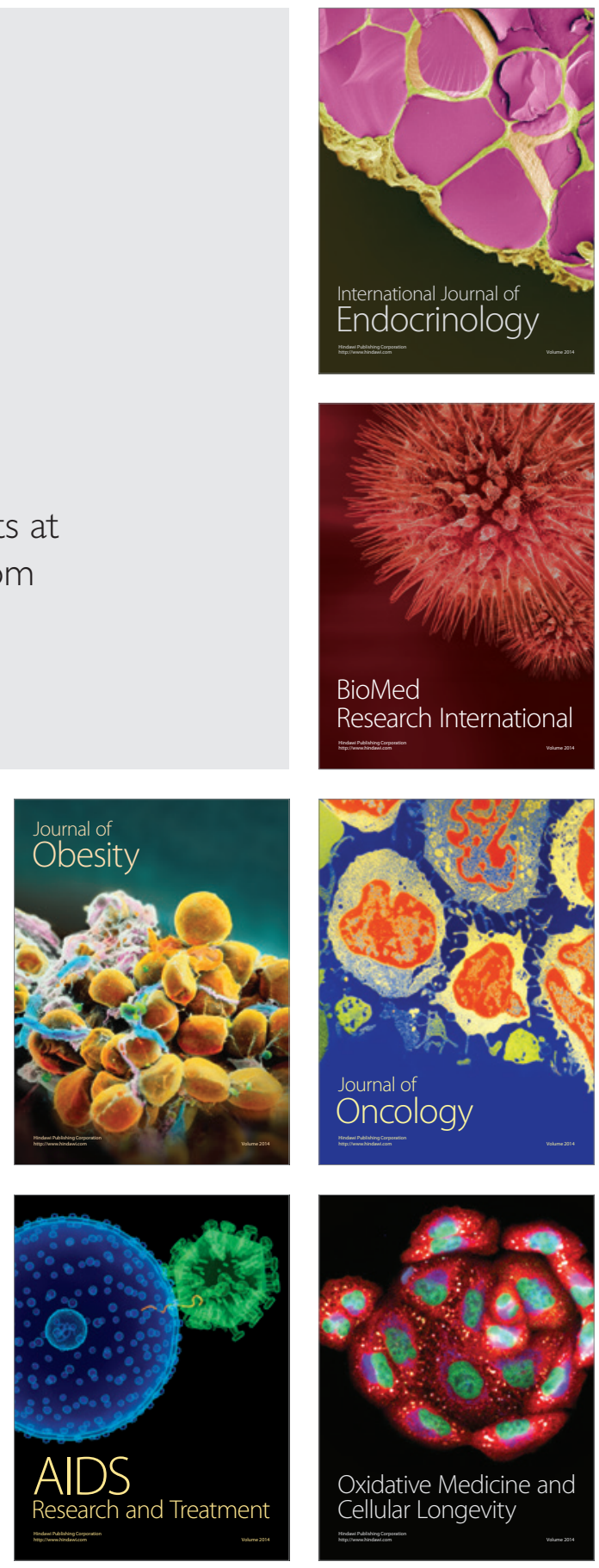